\title{
Dynamics of the structural state and enzymatic activity of calcic chernozem under the influence of biologically active drugs
}

\author{
Marina Dubinina ${ }^{1,}$, Olga Bezuglova ${ }^{1}$, Vladimir Lychman ${ }^{1}$, Olga Naimi $^{1}$, and Elena \\ Polienko $^{1}$ \\ ${ }^{1}$ Federal State agrarian research center of Rostov, 1 Institutskaya street, village Rassvet, Aksay \\ district, 346735 Rostov region, Russia
}

\begin{abstract}
The results of many years of research on the individual and complex effects of biologically active substances on the structural state and enzymatic activity calcic chernozem - humic preparation Lignohumate and microbiological fertilizer "Baikal-EM" - are presented. It was found that biologically active substances contribute to an increase in enzymatic activity, humus content and an improvement in the state of the soil structure. When both preparations are applied directly to the soil, the maximum effect and statistical reliability of this effect on the structural characteristics of the soil are shown even under extremely unfavorable weather conditions. At the same time, the structural coefficient during the study period increases from 1.5 to $2-2.7$ in comparison with the background variant, which makes it possible to assess the structural state of the soils as "excellent". In general, the activity of enzymes during the research in the cultivation of winter crops tended to stable growth. The cessation of the application of liquid complex fertilizers and the transition to a spring crop led to a decrease in the activity of enzymes and their return to background values.
\end{abstract}

\section{Introduction}

Modern methods of maintaining and increasing the pace of agricultural production largely depend on the use of synthetic chemicals, complex equipment and aggregates, which often leads to a deterioration in the quality of the environment and the manifestation of the effect of degradation of productive soils. To overcome these negative consequences, new technologies and preparations are being introduced and adapted to preserve and restore soil fertility, as the main component of the food security program. [1-2].

Soil as a source of elements of mineral nutrition for plants, a moisture storage, a habitat for microbiological communities that carry out gas exchange and circulation of organic matter, is extremely sensitive to changes in its structural properties, which are closely related to all internal and external soil processes. The vital activity of most soil microorganisms is confined to soil aggregates that retain its water resistance and stability of its structure due to

* Corresponding author: dubinina-marina@rambler.ru 
mineral and organic bonds [3]. Many biochemical processes occur at biogeochemical interfaces, namely on the surface of soil aggregates, in the volume of pores, in the liquid and gas phase that fills it [4].

In this regard, it is very important to study the soil structure as a diagnostic characteristic for predicting intrasoil processes, the potential of soil fertility, and the possibility of preserving moisture reserves [5].

Intensive use of means of mechanization for tillage in agriculture leads to the fact that its natural constitution and density, water and gas exchange are disturbed, and resistance to erosion processes changes [6]. Minimizing soil cultivation contributes to an increase in the amount of macroaggregates, bioavailable carbon and the development of microbial biomass, metabolic diversity and the ability to perform the functions of a soil ecosystem [7]. However, even under conditions of intensive mechanized farming and the use of chemicals, it is possible to reduce the rate of degradation processes in the soil and reduce its potential harm to a minimum [8].

One of the ways out of this problem is to use the potential of the soil microflora itself, as well as artificial introduction of effective organic and biological agents - biostimulants, feeding and stimulating the development of the rhizosphere and catalyzing enzymatic activity, and, accordingly, plant growth. It is also important that biological products have waterproof adhesive properties due to its specific composition, and the mechanism of artificial structure formation is realized $[9,10]$. The use of biostimulants based on humic acids has proven itself to increase the productivity of crops, its resistance to adverse weather conditions and increased doses of pesticides. A number of researchers note the positive effect of these preparations on the agrophysical and microbiological properties of the soil: the quality of the agronomically valuable structure improves, the proportion of water-resistant aggregates increases, and the growth of ammonifiers and aminoautotrophic groups of microorganisms is noted $[11,12,13]$. Despite the ambiguity of the results of the use of biostimulants, the production, range and market for its use is increasing annually, which, given the environmental friendliness of these drugs, allows us to consider them a universal tool for solving many problems of agro-industrial production $[14,15]$.

\section{Materials and research methods}

The field experiment was established in the fall of 2009 and continued until 2012 on the territory of a pilot farm in the Myasnikovsky district of the Rostov region. The experimental site is located at calcic chernozem (loamic). The field experiment was carried out in 6 repetitions according to the scheme:

Table 1. Experiment scheme

\begin{tabular}{|l|c|c|}
\hline \multicolumn{1}{|c|}{ Variant } & Lignohumate & $\begin{array}{c}\text { Baikal- } \\
\text { EM }\end{array}$ \\
\hline $\begin{array}{l}\text { 1 Background (liquid complex fertilizer NP } \\
\text { 10:34) }\end{array}$ & - & - \\
\hline $\begin{array}{l}\text { 2 Background + Lignohumate (leaf } \\
\text { treatment) }\end{array}$ & $0.751 / \mathrm{ha}$ & - \\
\hline 3 Background + Lignohumate (tillage) & $1.01 / \mathrm{ha}$ & - \\
\hline $\begin{array}{l}4 \text { Background + Lignohumate (tillage) }+ \\
\text { Baikal-EM (tillage) }\end{array}$ & $1.01 / \mathrm{ha}$ & $\begin{array}{c}3.01 / \\
\mathrm{ha}\end{array}$ \\
\hline 5 Background + Baikal-EM (tillage) & - & $\begin{array}{c}3.01 / \\
\mathrm{ha}\end{array}$ \\
\hline
\end{tabular}

Plot size $-25 \mathrm{~m}^{2}$ 
Background - liquid complex nitrogen-phosphorus nitrate-free fertilizer NP 10:34 with an increased content of nutrients (LC).

Microbiological fertilizer "Baikal-EM" and growth stimulator Lignohumate were used as biologically active preparations. "Baikal-EM" - is a liquid concentrate created using a special technology of effective microorganisms (EM-technology), consisting of populations of microorganisms with different ecological strategies: lactic acid bacteria, saccharomycetes and purple non-sulfur bacteria. This drug supports and stimulates the natural soil microflora, activates the mobilization of phosphorus, microbial nitrogen fixation and photosynthesis. Lignohumate was also introduced into the experiment scheme - a highly effective preparation based on humic compounds obtained from pulp and paper industry waste. The total content of salts of humic substances in the dry matter of Lignohumate is not less than $90 \%$. The drug contains humates of potassium, sodium, calcium, a complex of micro- and macroelements in a chelated form. Treatment of plants and soil with solutions of these preparations was carried out at the rate of $3001 /$ ha of working solution.

Cereals were cultivated on the experimental site: 2009, 2010. winter wheat, 2012 spring barley.

The observations were carried out in dynamics. Samples were taken from the arable horizon during the growing season of winter wheat: before fertilization $(09 / 27 / 2009$, $09 / 19 / 2010,09 / 22 / 2011$ ), after fertilization (germination phase) $(05 / 10 / 2010,04 / 22 / 2011$ ), in the heading phase (06/23/2010) and after harvest (08/07/2010,08/20/2011); during the growing season of spring barley - in the germination phase (15.04.2012) and the earing phase (07.07.2012).

Soil samples were taken in accordance with GOST 28186-89. The humus content was determined according to GOST 26213-91 (Russian State Standard, 1991) based on the Tyurin method by oxidation of organic matter with a potassium dichromate solution in sulfuric acid. In soil samples, the enzymatic activity, catalase, was also determined by the gasometric method of A.Sh. Galstyan and invertase using the modified colorimetric method of F.Kh. Khaziev. To determine the state of the soil structure, we used "dry" and "wet" sieving according to the method of N.I. Savinov and the determination of the water resistance of soil aggregates by the method of P.I. Andrianov as modified by N.A. Kachinsky. Statistical and graphical data processing was carried out using the methods of mathematical statistics and MS Excel.

\section{Results and discussion}

Control of the humus content is one of the main tasks, since the humus content of the soil is not only directly related to the change in all soil properties, but also clearly reflects the influence of external positive and negative processes on these properties. Figure 1 clearly demonstrates that the humus content in the soil when the biological preparation "Baikal-EM" is added with and without Lignohumate is higher than in the background variant, in which the processes of formation and destruction of humus take place without their additional initiation.

In almost all variants, a slight increase in the humus content is noted, a slight decrease is found in the last two samples. This is a consequence of the removal of substances from the soil with the harvest and a decrease in the aftereffect of the applied fertilizers. The different speed of these processes is also associated with the duration of the growing season of cultivated crops. The calculation of the Student's criterion showed that the change in the humus content is reliable only in option 4 with the joint introduction of two biologically active substances and in some selections in options 3 and 5, where the individual application of humic fertilizer and microbiological preparation was carried out directly into the soil. 


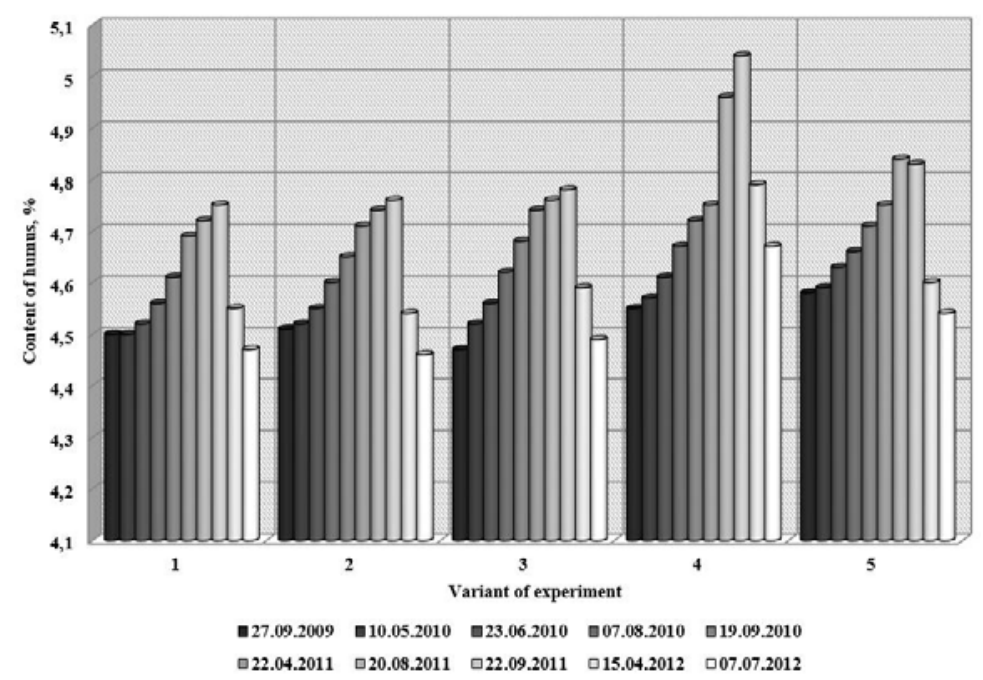

Fig. 1. Dynamics of the humus content in calcic chernozem according to the variants of the experiment with biologically active substances: 1 Background; 2 Background + Lignohumate (leaf treatment); 3 Background + Lignohumate (tillage); 4 Background + Lignohumate (tillage) + BaikalEM (tillage); 5 Background + Baikal-EM (tillage)

The change in the humus content of the soil could not but affect the state of structural units. An important indicator of the quality of the structure is the structural coefficient, calculated as the ratio of the number of agronomically valuable aggregates to agronomically non-valuable ones. The change in the structure coefficient for the variants of the experiment is shown in Fig. 2. There is a gradual increase in the number of agronomically valuable units. In the variants with the introduction of biological products directly into the soil, this process is more intensive, especially clearly shown by the dynamics of the values of the structural coefficient at the beginning of the experiment in 2009 and after the harvest in 2011. These results indicate that the use of biologically active preparations has a beneficial effect on the structure of the soil. In the aftereffect, the influence of active substances on this indicator decreases, and the values of the structural coefficient tend to their natural level (background). 


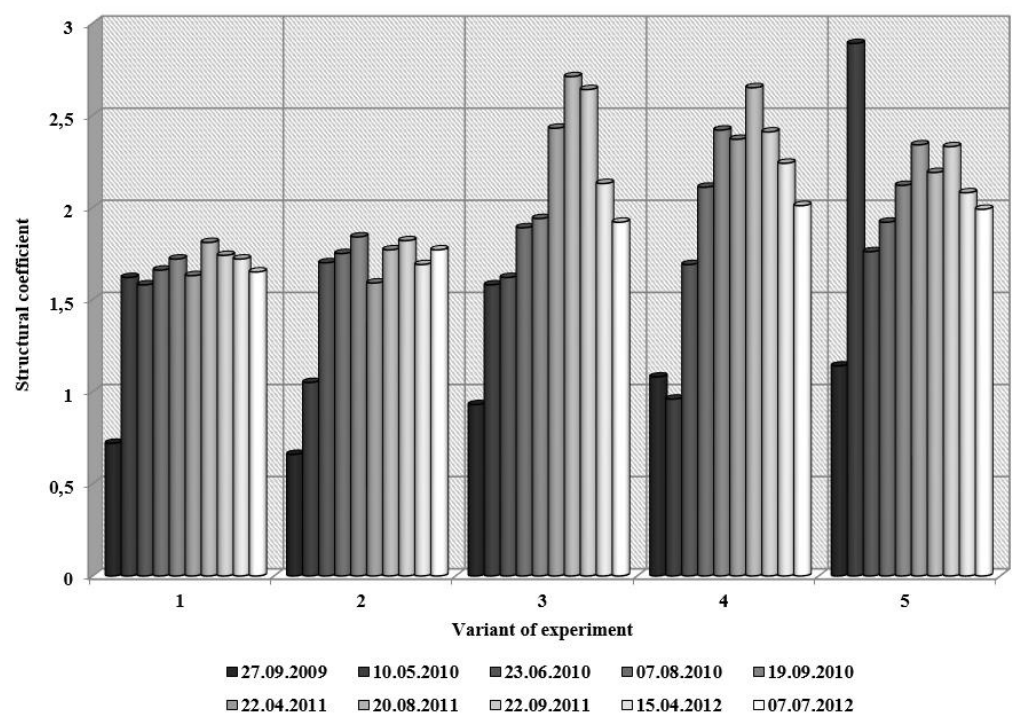

Fig. 2. Dynamics of the structural coefficient in calcic chernozem according to the variants of the experiment with biologically active substances:1 Background; 2 Background + Lignohumate (leaf treatment); 3 Background + Lignohumate (tillage); 4 Background + Lignohumate (tillage) + BaikalEM (tillage); 5 Background + Baikal-EM (tillage)

Lignohumate treatment of crops "on the leaf" did not make significant changes in the structural state of chernozem, but foliar treatment has a much more favorable effect on the qualitative characteristics of the vegetating plants themselves (a link is needed here).

Another important indicator of the state of the soil structure is the number of waterresistant aggregates. The resistance of aggregates to the effects of raindrops and water flows is an indicator describing the effect of aggregate size on the erodibility of row spacings and fallow fields on semi-arid soils [16].

According to the Savinov method, it is determined using the "wet" sieving method. In the summer months of the growing season of 2009-2010 in this region of the Rostov region, the air temperature was $+30-35{ }^{\circ} \mathrm{C}$, the atmospheric humidity was kept below $30 \%$. These conditions and the extremely low amount of rainfall ensured the onset of severe drought, which, combined with wind, negatively affected the condition of the soil. According to the results of "dry" sieving, this tendency is weakly noticeable, but the content of water-resistant aggregates showed a more pronounced trend towards a deterioration in soil structure. Figure 3 shows that during this period the water resistance of the soil in the background variant is subject to maximum changes, however, later this tendency is smoothed out, and the water resistance of the aggregates increases. 


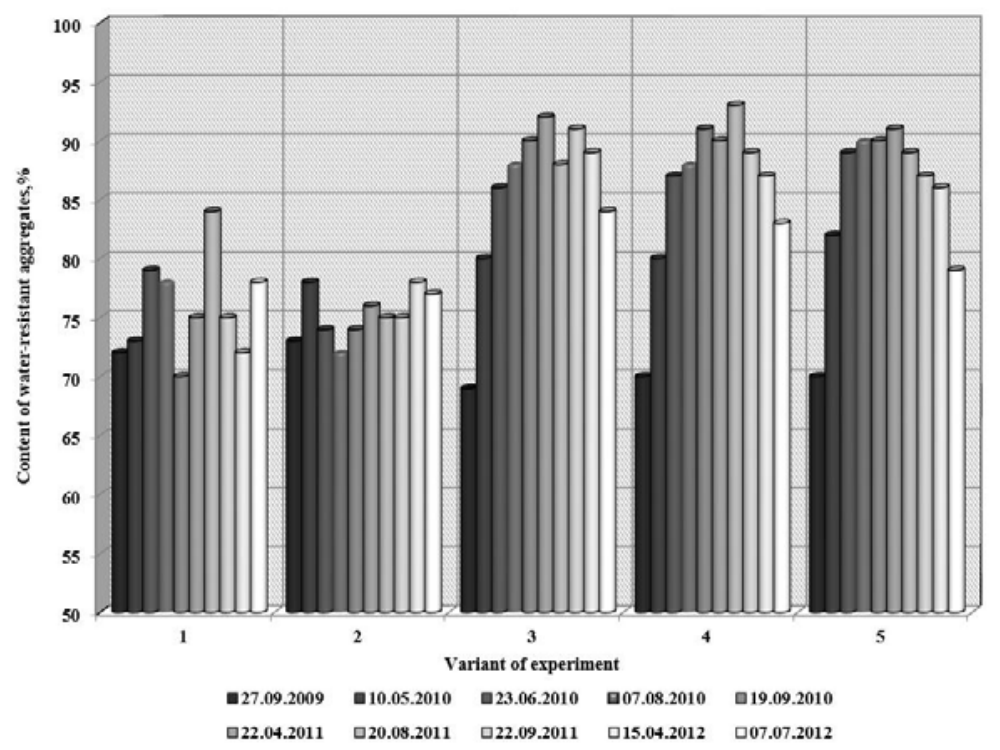

Fig. 3. Content of water-resistant aggregates by the method of "wet " sieving in calcic chernozem according to the variants of the experiment with biologically active substances: 1 Background; 2 Background + Lignohumate (leaf treatment); 3 Background + Lignohumate (tillage); 4 Background + Lignohumate (tillage) + Baikal-EM (tillage); 5 Background + Baikal-EM (tillage)

The study also shows an insignificant difference between the background variant and the variant with foliar treatment of plants. However, the introduction of biologically active drugs directly into the soil (options $3,4,5$ ) allows you to preserve water-resistant aggregates and even increase their content, which once again confirms the anti-stress effect of these drugs. The relative stability of high values of soil water resistance indices testifies to the effectiveness of its influence on microbiotic activity in the root layer. Thus, the introduction of these preparations into the soil makes it possible to assess its structural characteristics as "excellent" on the Dolgov-Bakhtin scale. However, after the termination of the introduction of drugs, the coefficient of water resistance tends to its initial level. For a more detailed study of the aftereffect of drugs, several more years are needed, therefore, some results can only be judged as a trend.

This phenomenon is due to the fact that plants release a certain amount of organic compounds into the root zone of the soil, while its total amount entering the soil from a plant by exosmosis reaches $5 \%$ of the dry weight of the assimilated mass. Moreover, different plants release certain types of substances into the soil. For example, amino acids are found in the secretions of leguminous plants; carbohydrates and organic acids predominate in cereals and other non-leguminous plants. In addition to these secretions, plants continuously shed dead epidermal cells and root hairs from the root surface, which are also a substrate for microorganisms to feed. The roots create in its immediate vicinity a zone most favorable for the development of biota [7, 10-11].

Indeed, the results of determining the activity of the enzyme catalase (Fig. 4) showed that the introduction of two preparations with different effects on the soil and its biological activity at once increases the activity of the enzyme most strongly. 


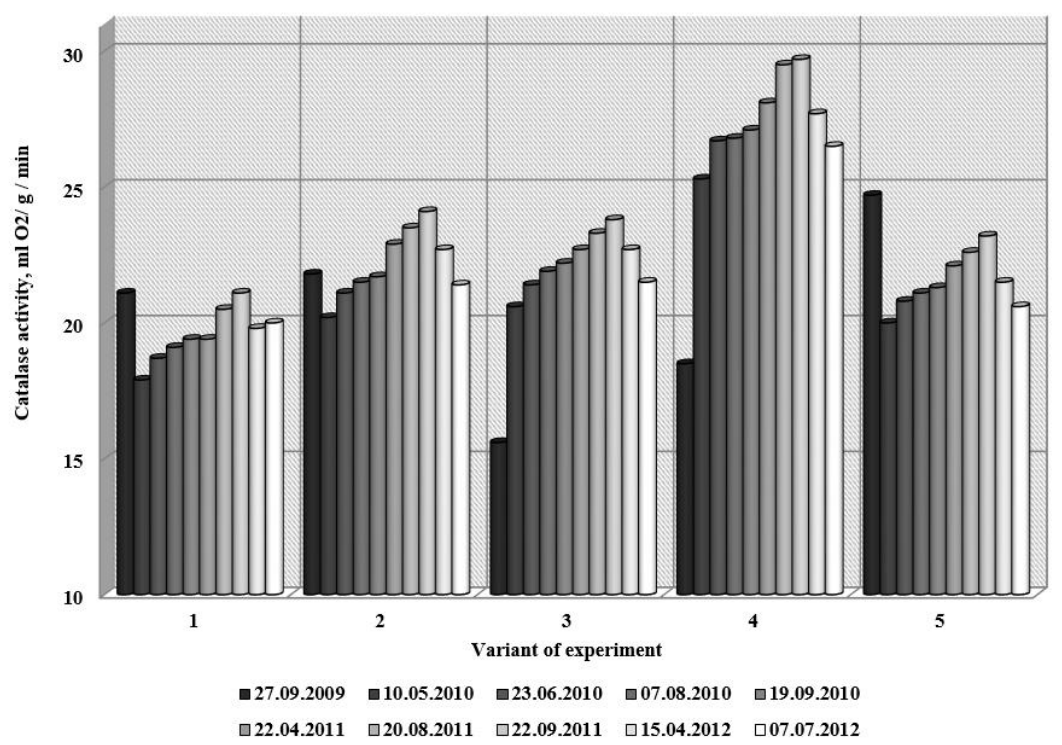

Fig. 4. Dynamics of catalase activity in calcic chernozem according to the experimental variants with biologically active substances, $\mathrm{ml} \mathrm{O} 2$ / g / min: 1 Background; 2 Background + Lignohumate (leaf treatment); 3 Background + Lignohumate (tillage); 4 Background + Lignohumate (tillage) + BaikalEM (tillage); 5 Background + Baikal-EM (tillage)

The reliability of the action of the drugs is confirmed statistically in the variant of their joint application, in other variants the effect is statistically insignificant. There is some increase in catalase activity in comparison with the background, however, the positive effect of the individual addition of Lignohumate and "Baikal-EM" on the catalase activity can only be spoken of as a trend.

The activity of invertase is less informative compared to catalase in assessing the aftereffect of the influence of biologically active drugs, however, the general nature of the changes remains here. In fig. 5 shows the dynamics of invertase activity during the entire observation period. 


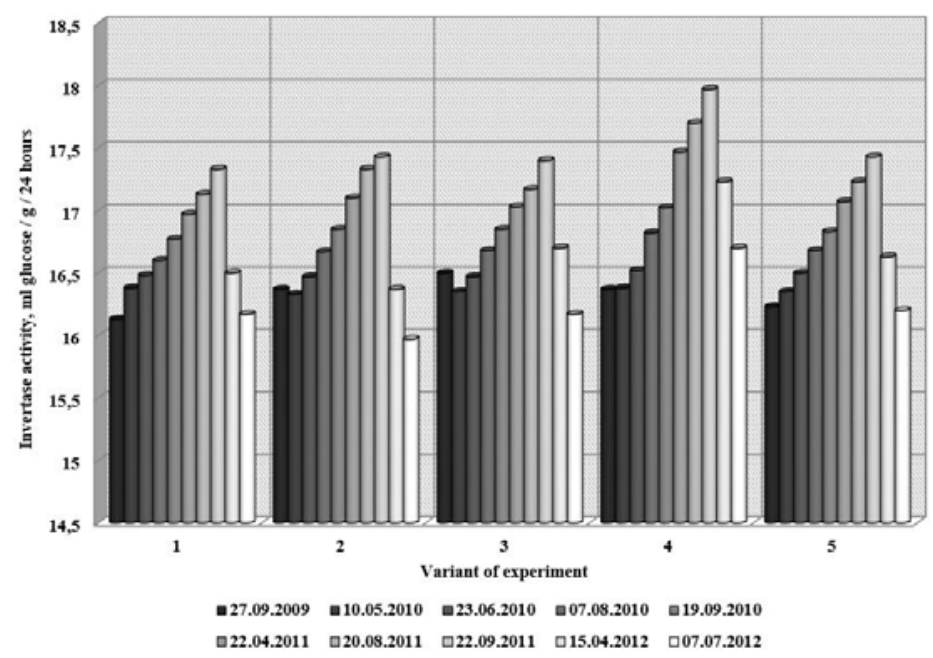

Fig. 5. Dynamics of invertase activity in calcic chernozem according to the variants of the experiment with biologically active substances, $\mathrm{ml}$ of glucose/ $\mathrm{g} / 24$ hours:1 Background ; 2 Background + Lignohumate (leaf treatment) ; 3 Background + Lignohumate (tillage); 4 Background + Lignohumate (tillage) + Baikal-EM (tillage); 5 Background + Baikal-EM (tillage)

In the background variant, the introduction of FCC initiated the activity of invertase, which is reliably confirmed by the results of studies during the growing season of winter wheat. This indicator demonstrated dynamic stability during the interaction of soil with components of biological preparations, and only the introduction of humates in combination with a microbiological preparation led to a statistically significant increase in invertase activity. The termination of the use of liquid complex fertilizer during the cultivation of spring barley led to a decrease in invertase activity, however, the complex of biologically active substances did not allow this indicator to return to the values of the background variant at the start of the experiment.

\section{Conclusion}

The introduction of Lignohumate into the soil, both independently and in a mixture with the microbiological preparation "Baikal-EM", contributes to an increase in the humus content in calcic chernozem by a statistically significant value. This is due to a set of favorable circumstances: an increase in yield is accompanied by an increase in the supply of crop residues, an increase in biological activity due to the use of the biological preparation "Baikal-EM" stimulates their transformation, the presence of humic substances included in Lignohumate promotes humification.

The use of biologically active fertilizers has a beneficial effect on the structure of the soil, the introduction of the preparations directly into the soil proved to be especially effective, while, even with different compositions and mechanisms of action, Lignohumate and "Baikal-EM" showed similar effects, which strengthened each other when both drugs. Thus, the dynamics of the structural coefficient was characterized by stable growth during the growing season of winter wheat and was not subject to significant seasonal influences. A decrease in this indicator during the cultivation of spring barley is associated with the termination of the application of fertilizers and preparations; in fact, only the aftereffect of the preparations was observed. The higher intensity of the growing processes of spring culture also affected. Similar trends can be traced in the study of the content of water-resistant 
aggregates in the soil. The ability of both drugs to exhibit adhesive properties, and thereby stabilize the water-resistant structure, manifested itself in a decrease in degradation processes.

The use of biologically active substances and mineral fertilizers (LCF) has a different effect on the enzymatic activity of ordinary carbonate chernozem. Invertase has shown inertness to the action of biological drugs, and only its combined use caused a slight increase in the activity of this enzyme. Catalase turned out to be more informative as an indicator of the processes occurring in the soil when biologically active substances are added. Catalase activity is much more pronounced in the variant of the combined use of Lignohumate and "Baikal-EM" in comparison with the background and other variants.

According to the results of the research, the treatment of vegetative plants with Lignohumate does not introduce any statistically significant changes in the structural and enzymatic state of chernozem. The most effective and favorable from the agrophysical point of view is the joint introduction of biological preparations directly into the soil, when the effect of the introduced lactic acid bacteria of the preparation "Baikal-EM" is enhanced by the humic substances of Lignohumate.

\section{References}

1. L. Shivlata, T. Satyanarayana, Agro-Environmental Sustainability. Actinobacteria in Agricultural and Environmental Sustainability, Springer, Cham 173-218 (2017) https://doi.org/10.1007/978-3-319-49724-2_9

2. J. D. Flores-Félix, E. Menéndez, R. Rivas, Ma de la Encarnación Velázquez, Organic Farming. Global Perspectives and Methods. A volume in Woodhead Publishing Series in Food Science, Technology and Nutrition. Chapter 9 - Future Perspective in Organic Farming Fertilization: Management and Product, 269-315 (2019) https://doi.org/10.1016/B978-0-12-813272-2.00010-0

3. R.L. Wilpiszeski, J.A. Aufrecht, S.T. Retterer, M.B. Sullivan, D.E. Graham, E.M. Pierce, O.D. Zablocki, A.V. Palumbo, D.A. Elias, Appl Environ Microbio. Soil aggregate microbial communities: Towards understanding microbiome interactions at biologically relevant scales 85(14) (2019) DOI: 10.1128/AEM.00324-19

4. H.P. Blume, et al., Scheffer/SchachtschabelSoil Science. Chemical Properties and Processes. In: Springer, Berlin, Heidelberg 123-174 (2016) https://doi.org/10.1007/9783-642-30942-7_5

5. E. Rabot, M. Wiesmeier, S. Schluter, H. J. Vogel, Geoderma. Soil structure as an indicator of soil functions: A review 314, 122-137 (2018) DOI: 10.1016/j.geoderma.2017.11.009

6. M. Lamandé, P. Schjønning. Soil Res. Soil mechanical stresses in high wheel load agricultural field traffic: A case study. 56, 129-135 (2018) doi:10.1071/SR17117

7. F.M. Vezzani, C. Anderson, E. Meenken, R. Gillespie, M. Peterson, M.H. Beare, Soil Tillage Res. The importance of plants to development and maintenance of soil structure, microbial communities and ecosystem functions 175, 139-149 (2018) doi:10.1016/j.still.2017.09.002

8. E. Pareja-Sánchez, D. Plaza-Bonilla, M.C. Ramos, J. Larnpurlanes, J. Alvaro-Fuentes, C. Cantero-Martinez, Soil Tillage Res. Long-term no-till as a means to maintain soil surface structure in an agroecosystem transformed into irrigation 174, 221-230 (2017) doi:10.1016/j.still.2017.07.012 
9. A. Sahu, et al., Microbes: Role of Rhizospheric Microbes in Soil. A Sustainable Approach for Enhancing Nutrient Availability in Agricultural Soils, Springer, Singapore 47-75 (2018) https://doi.org/10.1007/978-981-13-0044-8_2

10. S. Macias-Benitez, A. M. Garcia-Martinez, P. C. Jimenez, J. M. Gonzalez, M. T. Moral, J. P. Rubio, Front. Plant Sci. Rhizospheric Organic Acids as Biostimulants: Monitoring Feedbacks on Soil Microorganisms and Biochemical Properties 11, 633 (2020) DOI: 10.3389/fpls.2020.00633

11. O.S. Bezuglova, A.V. Gorovtsov, E.A. Polienko, et al., J Soils Sediments. Effect of humic preparation on winter wheat productivity and rhizosphere microbial community under herbicide-induced stress. 19, 2665-2675 (2019) https://doi.org/10.1007/s11368018-02240-Z

12. V.A. Lykhman, A.I. Klimenko, M.N. Dubinina, O.I. Naimi, E.A. Polienko, Innovative Technologies in Science and Education (ITSE-2020), Divnomorskoe village, Russian Federation, E3S Web of Conferences, Influence of humic preparations on the content of carbohydrates in structural units and their water resistance, 210, id.04005. DOI: 10.1051/e3sconf/202021004005

13. V.A. Lykhman, A.I. Klimenko, M.N. Dubinina, et al., Zemledelie. Russian. The influence of treating crops with the tank mixture of the humic preparation and the herbicide on the aggregate composition of chernozem. 8, 3-7 (2020) doi: 10.24411/00443913-2020-10801

14. P. Calvo, L. Nelson, J. W. Kloepper. Plant and Soi.l Agricultural uses of plant biostimulants 383, 3-41 (2014). https://doi.org/10.1007/s11104-014-2131-8

15. Y. Bashan, L.E. de-Bashan, S.R. Prabhu, et al., Plant Soil. Advances in plant growthpromoting bacterial inoculant technology: formulations and practical perspectives (1998-2013) 378, 1-33 (2014) https://doi.org/10.1007/s11104-013-1956-x

16. A. R. Vaezi, S. F. Eslami, S. Keesstra, CATENA. Interrill erodibility in relation to aggregate size class in a semi-arid soil under simulated rainfalls 167, 385-398 (2018) ISSN 0341-8162, https://doi.org/10.1016/j.catena.2018.05.003. 